\title{
Exploring hospital compliance with the primary nursing care model: validating an inventory using the Delphi method
}

\author{
Antonello Cocchieri ${ }^{1,2^{*}}$ D, Giorgio Magon ${ }^{3}$, Manuela Cavalletti ${ }^{1}$, Elena Cristofori ${ }^{4}$ and Maurizio Zega ${ }^{1}$
}

\begin{abstract}
Background: The primary nursing care model is considered a personalized model of care delivery based on care continuity and on the relationship between the nurse and patient. Primary nursing checklists are not often mentioned in the literature; however, they represent a valid instrument to develop, implement, and evaluate primary nursing. The aim of this study was to create a structured checklist to explore hospital compliance in primary nursing.
\end{abstract}

Methods: The Delphi method was used to develop and validate a checklist. The preliminary version was created and sent to three experts for their opinions. Their comments were ultimately used in the first version, which included four components with 19 items regarding primary nursing characteristics. A two-round Delphi process was used to generate consensus items. The Delphi panel consisted of six experts working in primary nursing contexts and/or teaching or studying primary nursing. Data were collected using a structured questionnaire from July 2020 to January 2021. These experts were asked to rate each element for relevance using a 4-point Likert-type scale. Furthermore, the consensus among the panel of experts was set at $\geq 78 \%$, with selected items being voted "quite relevant" and "highly relevant". Content validity index (I-CVI) and modified kappa statistic were also calculated. Following expert evaluation, the first version of the checklist was modified, and the new version, constituting 17 items, was sent to the same experts.

Results: The first version of the checklist demonstrated a main relevance score of 3.34 (SD $=0.83$; range $=1.3-4$; mean I-CVI =0.84; range: 0.83-1), but three items did not receive an adequate I-CVI score, that is, lower than 0.78 . After the second round, the I-CVIs improved. The main score of relevance was 3.61 (SD: 0.35; range = 2.83-4; mean $=1-C V I:$ 0.93). The S-CVI/UA was 0.58 , and the S-CVI/Ave was 0.93 .

Conclusion: Measuring primary nursing compliance should be implemented to provide continuous feedback to nurses. Moreover, utilizing valid checklists could permit comparing different results from others' research. Future research should be conducted to compare the results from the checklist with nursing outcomes.

Keywords: Content validity, Primary nursing, Checklist, Delphi method, Content validity index

\footnotetext{
* Correspondence: antonello.cocchieri@policlinicogemelli.it

${ }^{1}$ Fondazione Policlinico A. Gemelli IRCCS, 00168 Rome, Italy

${ }^{2}$ Section of Hygiene, Woman and Child Health and Public health, Università

Cattolica del Sacro Cuore, Largo Francesco Vito 1, 00168 Rome, Italy

Full list of author information is available at the end of the article
}

\section{$\triangle B M C$}

(c) The Author(s). 2021 Open Access This article is licensed under a Creative Commons Attribution 4.0 International License, which permits use, sharing, adaptation, distribution and reproduction in any medium or format, as long as you give appropriate credit to the original author(s) and the source, provide a link to the Creative Commons licence, and indicate if changes were made. The images or other third party material in this article are included in the article's Creative Commons licence, unless indicated otherwise in a credit line to the material. If material is not included in the article's Creative Commons licence and your intended use is not permitted by statutory regulation or exceeds the permitted use, you will need to obtain permission directly from the copyright holder. To view a copy of this licence, visit http://creativecommons.org/licenses/by/4.0/ The Creative Commons Public Domain Dedication waiver (http://creativecommons.org/publicdomain/zero/1.0/) applies to the data made available in this article, unless otherwise stated in a credit line to the data. 


\section{Background}

Nursing care delivery models (NCDMs) are defined as specific forms of care delivery in response to demographic, organisational, and healthcare environment changes [1]. In the literature, NCDMs are described as independent or collaborative approaches by nurses to provide direct care to a group of patients [2]. Over time, traditional NCDMs have evolved based on economics from the 1930s to the present and include approaches, such as total patient care, functional care, team nursing care, and the primary nursing care model (PN) [3]. They can differ from each other in terms of philosophy, the conceptual model utilized, work allocation, nursing staff, patient allocation, skill mix, and costs, with the common goal of improving the quality of nursing care [4].

$\mathrm{PN}$ is considered a personalized model of care delivery based on care continuity and on the relationship between nurses and patients. PN can be described as a delivery system comprised of four organisational elements, which differentiate PN from other systems, such as functional nursing or team nursing [3]. These elements are summarised in four principal points: a) responsibility for relationship and decision-making, b) work allocation and patient assignments, c) communication among staff members, and d) management and leadership philosophy [5]. In $\mathrm{PN}$, the primary nurse is responsible for several patients $24 \mathrm{~h}$ per day, 7 days a week, including during off-duty hours. The primary nurse is a registered nurse responsible for planning, providing, and evaluating the care of patients throughout their stay in hospitals [6, 7].

Evaluating the impact of NCDMs is a fundamental part of clinical practice improvement, and the evaluation of hospital compliance with related principles and organisational rules is the first base element [8]. Even though the term "compliance" has many definitions [9], we approach it from an evaluative perspective [10]. In particular, we consider compliance as behaviour conforming to rules or specific standards, such as PN principles.

Studies that have evaluated the impact of PN have used both quantitative and qualitative methods [5, 11]. Studies related to $\mathrm{PN}$ have utilized different outcomes for determining their efficacy, such as the effect on care quality [12], positive patient experience [12, 13], costs [14], or other nursing outcomes [11, 15]. However, various difficulties have been discovered in analysing these studies because PN differs in terms of the manner and time in which it is implemented $[12,14]$. These results are often incomparable because certain elements of PN remain unclear or unspecified $[14,15]$.

To facilitate the development, implementation, and evaluation of an NCDM, focusing on the role of nursing [16] in terms of development strategies [17] and system evaluation control is crucial [18].
One way to evaluate the implementation of processes is by using checklists [19], which are used in many contexts to aid decision-making [20]. A checklist is a structured inventory that outlines the criteria of consideration for a specific process $[19,20]$. They are used to remember all relevant criteria that should be considered in one particular aspect. The introduction of checklists in healthcare has had a positive effect in terms of improving the quality of care and reducing negative outcomes [21]. The literature recommends using standardised methodologies for checklist design [22].

PN checklists are lacking in the literature. Because checklists are a valid instrument to develop, implement, and evaluate $\mathrm{PN}$, the aim of this study is to create a structured checklist to explore hospital compliance with the PN.

\section{Methods}

This is a methodological study employing the Delphi method [23] to develop and validate a checklist to evaluate compliance in a specific hospital setting with PN elements based on the main principles described by Manthey [7].

\section{Development of a checklist to evaluate compliance in a hospital setting with PN elements}

The preliminary version was created by two researchers in nursing science to evaluate hospital adherence to PN principles. The authors developed a preliminary version based on the discussion about the main areas constituting $\mathrm{PN}$ : (a) the decision-making process (the primary nurse should be responsible for patient-centered decision-making); (b) work allocation and/or patient assignment (strategies for daily care and for assigning the nurse to do this care); (c) communication (direct interpersonal communication with other staff about the patient); and (d) accountability (being accountable for the quality of care provided for a fixed caseload of patients $24 \mathrm{~h}$ a day, 7 days a week) [5]. The researcher included items referring to these areas.

This preliminary version was sent to a professor in nursing science and two nursing service managers to give their opinion about the items and suggest other relevant aspects to complete the inventory tool. The nursing service managers were experts in applying $\mathrm{PN}$, as they have developed and implemented PN since 2010 in two Italian academic hospitals. Comments were collected using a checklist with the possibility of entering any comment in free text per each item. The checklist was sent via email from February 2020 to March 2020 after obtaining the experts' written consent.

At the end of this revision, the structure of the first version of the checklist included four areas: decisionmaking process (five items), work allocation and patient 
assignment (five items), communication (five items), and accountability (four items), with a total of 19 items regarding primary nursing characteristics (Additional file 1). Moreover, the first version of the checklist was created with the option of entering any comment in free text.

\section{Validation of the checklist}

In the first round of evaluation, the first version of the checklist was sent to six nurse experts in PN, who belonged to a panel of experts [23]. Four of them had contributed to the development of a PN model in hospital settings. The selection criteria for the expert panel included a minimum of 2 years of experience working with $\mathrm{PN}$ and/or teaching or studying this nursing care model. Four females and two males constituted the panel. They had a mean age of 38 years ( \pm 9.8; range: $30-50$ ) and had been employed as registered nurses for a mean of 14.6 years $( \pm 11.78$; range: 4-30). Their professional roles ranged as follows: nursing clinical care $(n=2)$, nursing management $(n=3)$, and one researcher in nursing science. Their academic titles were Bachelor of Nursing Science $(n=2)$, Master of Science in Nursing $(n=3)$, and Doctor of Philosophy in Nursing $(n=1)$. These experts were asked to rate each element for relevance using a 4-point Likert-type scale $(1=$ not relevant, $2=$ somewhat relevant, $3=$ quite relevant, and $4=$ highly relevant) according to Lynn, Polit, and Beck [24]. They were also asked to provide comments at the end of the checklist to add any other useful element. Data were collected using a structured questionnaire from July 2020 to November 2020 after obtaining the experts' written consent to participate.

The responses were used to calculate the content validity at the item and scale levels. The content validity of individual items (I-CVI) was calculated as the number of experts giving a rating of 3 or 4 (dichotomizing the scale into relevant and not relevant) divided by the total number of experts [23, 24]. As recommended by Lynn, I-CVI should not be lower than 0.78 [23].

Also, a multi-rater Kappa statistic was used to adjust I-CVI for chance agreement $[25,26]$. The Kappa is a consensus index used to test inter-rater agreement among experts who rate dichotomous categories of data and indicates beyond chance the relevance of the item [25-27]. A modified Kappa (K*) [25, 26] value was computed using the following formula: $\mathrm{K}^{*}=\left(\mathrm{I}-\mathrm{CVI}-\mathrm{P}_{\mathrm{C}}\right) /$ $\left(1-\mathrm{P}_{\mathrm{C}}\right) \cdot \mathrm{P}_{\mathrm{C}}$ is the probability of chance agreement and was calculated for each item with the following formula: $\mathrm{P}_{\mathrm{C}}=[\mathrm{N}$ ! /A! $(\mathrm{N}-\mathrm{A}) !] * 0.5^{\mathrm{N}}[25]$, where $\mathrm{N}=$ number of experts, and $\mathrm{A}=$ number of experts who agree the item is relevant. $K^{*}$ values above 0.74 were considered excellent, between 0.60 to 0.74 good, and 0.40 to 0.59 fair. Values should not be lower than 0.60 [25].
Finally, the content validity at the scale level was measured through the scale-level content validity index, the universal agreement calculation method (S-CVI/UA), and the average of the I-CVIs for all items of the scale (S-CVI/Ave). The S-CVI/UA was calculated as the proportion of total agreement (from I-CVI scores) by all the experts, and the S-CVI/Ave as the average of all I-CVIs.

\section{Second version of checklist}

After the first round, the first version of the checklist was modified, and the new version (second version-see Additional file 2), constituting 17 items, was sent to the same experts as recommended in [23, 24]. The response rates were calculated in the same manner as in the first round. Data were collected from December 2020 to January 2021.

\section{Final version of the checklist}

The final version of the checklist was sent to the same experts for final approval, and they were asked to add any comments they may have.

\section{Results \\ Development of the checklist to evaluate the compliance of hospital setting to PN elements}

During the development of the preliminary version of the checklist, three experts helped improve the items. They contributed by adding aspects regarding the nurses' competence evaluations and their patients' assignment modalities. In particular, they expressed the necessity to monitor and evaluate the compliance of wards to $\mathrm{PN}$ to evaluate the impact on nursing outcomes. Some statements are reported below.

"This inventory could be a way to improve nursing quality. This could be considered a good system to control compliance. This inventory could be used as tracer methodology."

"Evaluating helps to learn how aspects could be improved and it's a good technique to learn."

"It's necessary to add an item on nurses' competences. The objective evaluation of PN improves the adherence of nurses equips."

These comments were used to improve and develop the first version of the checklist.

\section{Validation of the checklist}

The first version of the checklist, after the first round, showed a main score of relevance of 3.34 (DS 0.83 . range $=1.3-4)$. The checklist showed an excellent I-CVI for 15 items out of a total of 19 (mean $\mathrm{I}-\mathrm{CVI}=0.83$; 
range: $0.83-1$ ), but three items did not receive an adequate I-CVI score, that is, lower than 0.78 according to Lynn (1986). Items receiving lower CVI ratings were consistent with items with lower Kappa coefficients (Table 1). A test score of an I-CVI of $\geq 0.78$ was equivalent to a probability of a $\mathrm{P}_{\mathrm{C}}<0.09$, indicating an excellent level of expert agreement concerning the test's relevance (Table 1 ).

Two items (Item 6, "There is evidence about who is the primary nurse of each impatient" and Item 9, "There is evidence of an evaluation of the nurses' competencies by a valid and reliable instrument") were removed because their I-CVI values were 0.16 and 0.33 , respectively, and because they referred to topics that were in other items. Item 6 was removed because it was already included in Item 16, "The name of the primary nurse is reported in the clinical documentation." Item 9 was removed because it was already included in Item 8 , "The competence of the primary nurse is evaluated by the nurse coordinator". Item 7 had an I-CVI of 0.66 and was modified as requested by experts from "There is evidence of primary nurse assignment by the nurse coordinator through weekly planning" to "There is evidence of primary nurse assignment by the nurse coordinator through planning." The S-CVI/UA was 0.47 , and S-CVI/ Ave was 0.83 .

\section{Second version and final approval of the checklist}

After the second round, the I-CVIs improved. The main score of relevance was 3.61 (DS: 0.35 ; range $=2.83-4$ ). The checklist showed an excellent I-CVI for all items, which ranged from 0.83 to 1 (mean I-CVI: 0.93). Also in

Table 1 I-CVI ratings and Kappa Score on a 19-item checklist by six experts: Items 3 and 4 on a 4-point Relevance Scale

\begin{tabular}{|c|c|c|c|c|c|c|c|}
\hline $\mathbf{N}$ & Item & $\begin{array}{l}\text { Number in } \\
\text { agreement }\end{array}$ & I-CVI & Interpretation & $P_{C}$ & $\mathrm{~K}^{*}$ & Interpretation \\
\hline 1 & $\begin{array}{l}\text { The primary nurse has a direct interpersonal communication with the } \\
\text { patient (the patient knows his/her primary nurse) }\end{array}$ & 6 & 1 & Relevant & 0.016 & 1 & Excellent \\
\hline 2 & $\begin{array}{l}\text { The primary nurse has a direct interpersonal communication with the } \\
\text { caregiver (the caregiver/family knows the patient's primary nurse) }\end{array}$ & 6 & 1 & Relevant & 0.016 & 1 & Excellent \\
\hline 3 & The primary nurse is able to introduce him/herself to the patient & 6 & 1 & Relevant & 0.016 & 1 & Excellent \\
\hline 4 & $\begin{array}{l}\text { The primary nurse (or nurse coordinator) delegates the care of the } \\
\text { patients to the associated care unit in case of any absences }\end{array}$ & 6 & 1 & Relevant & 0.016 & 1 & Excellent \\
\hline 5 & $\begin{array}{l}\text { There is evidence of face-to-face interactions between nurses and } \\
\text { patients }\end{array}$ & 5 & 0.83 & Relevant & 0.094 & 0.81 & Excellent \\
\hline 6 & There is evidence about who is the primary nurse of each inpatient & 1 & 0.16 & Eliminated & 0.094 & 0.07 & Unacceptable \\
\hline 7 & $\begin{array}{l}\text { There is evidence of primary nurse assignment by the nurse } \\
\text { coordinator through weekly planning }\end{array}$ & 4 & 0.66 & Modified & 0.234 & 0.57 & Fair \\
\hline 8 & $\begin{array}{l}\text { The competence of the primary nurses is evaluated by the nurse } \\
\text { coordinator }\end{array}$ & 6 & 1 & Relevant & 0.016 & 1 & Excellent \\
\hline 9 & $\begin{array}{l}\text { There is evidence of an evaluation of the nurses' competencies by } \\
\text { a valid and reliable instrument }\end{array}$ & 2 & 0.33 & Eliminated & 0.234 & 0.12 & Unacceptable \\
\hline 10 & There is no evidence of practicing other nursing care models & 5 & 0.83 & Relevant & 0.094 & 0.81 & Excellent \\
\hline 11 & $\begin{array}{l}\text { The primary nurse has direct interpersonal communication with the } \\
\text { physician concerning the clinical status of the patient }\end{array}$ & 5 & 0.83 & Relevant & 0.094 & 0.81 & Excellent \\
\hline 12 & $\begin{array}{l}\text { The primary nurse has direct interpersonal communication with } \\
\text { other members of the staff concerning the patient and his/her } \\
\text { clinical status }\end{array}$ & 5 & 0.83 & Relevant & 0.094 & 0.81 & Excellent \\
\hline 13 & $\begin{array}{l}\text { The primary nurse is accountable for the quality of the care } \\
\text { provided to the patient }\end{array}$ & 6 & 1 & Relevant & 0.016 & 1 & Excellent \\
\hline 14 & $\begin{array}{l}\text { The patient is well-informed by the primary nurse about the details } \\
\text { of his/her care plan }\end{array}$ & 5 & 0.83 & Relevant & 0.094 & 0.81 & Excellent \\
\hline 15 & $\begin{array}{l}\text { Daily focuses are organised among nurses on the main needs of } \\
\text { patients }\end{array}$ & 5 & 0.83 & Relevant & 0.094 & 0.81 & Excellent \\
\hline 16 & $\begin{array}{l}\text { The name of the primary nurse is reported in the clinical } \\
\text { documentation }\end{array}$ & 6 & 1 & Relevant & 0.016 & 1 & Excellent \\
\hline 17 & The nursing plan of care is reported in the clinical documentation & 6 & 1 & Relevant & 0.016 & 1 & Excellent \\
\hline 18 & There is evidence of the patient's evaluation within $24 \mathrm{~h}$ of admission & 6 & 1 & Relevant & 0.016 & 1 & Excellent \\
\hline 19 & There is evidence of the patient's evaluation after 7 days of hospitalisation & 5 & 0.83 & Relevant & 0.094 & 0.81 & Excellent \\
\hline
\end{tabular}

I-CVI Item-level content validity index, $P_{C}$ probability of a chance occurrence, $K^{*}$ Modified Kappa index 
this version, items receiving lower CVI ratings were consistent with items with lower Kappa coefficients (Table 2).

Consensus items generated from the first and second rounds are shown in Table 3.

The S-CVI/UA was 0.58 , and the S-CVI/Ave was 0.93 (Table 4).

In the final approval, no additional comments were expressed.

\section{Discussion}

This study presents quantity indices for content validity and a new checklist that assesses areas of PN relating to the principal four elements of the associated framework [7]. We previously did not find any research involving the development of inventory to monitor hospital compliance with the PN. Various studies have identified specific characteristics in defining the development process of PN [12-14], but evidence about a valid tool was not found.

Our results demonstrate an improvement in the I-CVI index at each round. They showed excellent agreement among experts in terms of item scoring after the second round. In the literature, the I-CVI index should be 1.00 if the experts are fewer than five. An I-CVI of at least 0.78 should be seen as adequate with six or more experts. I-CVI rates were considered in changing or revising any items in our draft.

Both S-CVI were calculated [24]. S-CVI/UA showed an improvement from 0.47 to 0.58 . When calculating SCVI/UA, the universal agreement of experts was considered, and if the number of experts increased, S-CVI/UA would be low [24]. For this reason, we calculated S-CVI/ Ave as recommended in [24]. Our results were higher than .90 , which showed an excellent average proportion of relevant rates ( 3 and 4 ) evaluated by experts.

Table 2 I-CVI ratings and Kappa Score on a 17-item checklist by six experts: Items 3 and 4 on a 4-point Relevance Scale

\begin{tabular}{|c|c|c|c|c|c|c|c|}
\hline $\mathbf{N}$ & Item & $\begin{array}{l}\text { Number in } \\
\text { agreement }\end{array}$ & $\mathrm{I}-\mathrm{CVI}$ & Interpretation & $P_{C}$ & $\mathrm{~K}^{*}$ & Interpretation \\
\hline 1 & $\begin{array}{l}\text { The primary nurse has a direct interpersonal communication with the } \\
\text { patient (the patient knows his/her primary nurse) }\end{array}$ & 6 & 1 & Relevant & 0.016 & 1 & Excellent \\
\hline 2 & $\begin{array}{l}\text { The primary nurse has a direct interpersonal communication with the } \\
\text { caregiver (the caregiver/family knows the patient's primary nurse) }\end{array}$ & 6 & 1 & Relevant & 0.016 & 1 & Excellent \\
\hline 3 & The primary nurse is able to introduce him/herself to the patient & 6 & 1 & Relevant & 0.016 & 1 & Excellent \\
\hline 4 & $\begin{array}{l}\text { The primary nurse (or nurse coordinator) delegates the care of the } \\
\text { patients to the associated care unit in case of any absences }\end{array}$ & 6 & 1 & Relevant & 0.016 & 1 & Excellent \\
\hline 5 & $\begin{array}{l}\text { There is evidence of face-to-face interactions between nurses and } \\
\text { patients }\end{array}$ & 5 & 0.83 & Relevant & 0.094 & 0.81 & Excellent \\
\hline 6 & $\begin{array}{l}\text { There is evidence of primary nurse assignment by the nurse } \\
\text { coordinator through a planning }\end{array}$ & 5 & 0.83 & Relevant & 0.094 & 0.81 & Excellent \\
\hline 7 & $\begin{array}{l}\text { The competence of the primary nurses is evaluated by the nurse } \\
\text { coordinator }\end{array}$ & 6 & 1 & Relevant & 0.016 & 1 & Excellent \\
\hline 8 & There is no evidence of practicing other nursing care models & 5 & 0.83 & Relevant & 0.094 & 0.81 & Excellent \\
\hline 9 & $\begin{array}{l}\text { The primary nurse has direct interpersonal communication with } \\
\text { the physician concerning the clinical status of the patient }\end{array}$ & 5 & 0.83 & Relevant & 0.094 & 0.81 & Excellent \\
\hline 10 & $\begin{array}{l}\text { The primary nurse has direct interpersonal communication with } \\
\text { other members of the staff concerning the patient and his/her } \\
\text { clinical status }\end{array}$ & 5 & 0.83 & Relevant & 0.094 & 0.81 & Excellent \\
\hline 11 & $\begin{array}{l}\text { The primary nurse is accountable for the quality of the care } \\
\text { provided to the patient }\end{array}$ & 6 & 1 & Relevant & 0.016 & 1 & Excellent \\
\hline 12 & $\begin{array}{l}\text { The patient is well-informed by the primary nurse about the details } \\
\text { of his/her care plan }\end{array}$ & 5 & 0.83 & Relevant & 0.094 & 0.81 & Excellent \\
\hline 13 & $\begin{array}{l}\text { Daily focuses are organised among nurses on the main needs of } \\
\text { patients }\end{array}$ & 6 & 1 & Relevant & 0.016 & 1 & Excellent \\
\hline 14 & $\begin{array}{l}\text { The name of the primary nurse is reported in the clinical } \\
\text { documentation }\end{array}$ & 6 & 1 & Relevant & 0.016 & 1 & Excellent \\
\hline 15 & The nursing plan of care is reported in the clinical documentation & 6 & 1 & Relevant & 0.016 & 1 & Excellent \\
\hline 16 & There is evidence of the patient's evaluation within $24 \mathrm{~h}$ of admission & 6 & 1 & Relevant & 0.016 & 1 & Excellent \\
\hline 17 & $\begin{array}{l}\text { There is evidence of the patient's evaluation after } 7 \text { days of } \\
\text { hospitalisation }\end{array}$ & 5 & 0.83 & Relevant & 0.094 & 0.81 & Excellent \\
\hline
\end{tabular}


Table 3 Consensus items generated from Rounds 1 and 2

\begin{tabular}{|c|c|c|c|c|c|c|}
\hline & \multicolumn{2}{|c|}{ Numbers in agreement } & \multicolumn{2}{|l|}{ I-CVI } & \multicolumn{2}{|l|}{$\mathrm{K}^{*}$} \\
\hline & First version & Second version & First version & Second version & First version & Second version \\
\hline 1 & 6 & 6 & 1 & 1 & 1 & 1 \\
\hline 2 & 6 & 6 & 1 & 1 & 1 & 1 \\
\hline 3 & 6 & 6 & 1 & 1 & 1 & 1 \\
\hline 4 & 6 & 6 & 1 & 1 & 1 & 1 \\
\hline 5 & 5 & 5 & 0.83 & 0.83 & 0.81 & 0.81 \\
\hline 6 & 1 & $\mathrm{R}$ & 0.16 & $\mathrm{R}$ & 0.07 & $\mathrm{R}$ \\
\hline 7 & 4 & M (5) & 0.66 & 0.83 & 0.57 & 0.81 \\
\hline 8 & 6 & 6 & 1 & 1 & 1 & 1 \\
\hline 9 & 2 & $\mathrm{R}$ & 0.33 & $\mathrm{R}$ & 0.12 & $\mathrm{R}$ \\
\hline 10 & 5 & 5 & 0.83 & 0.83 & 0.81 & 0.81 \\
\hline 11 & 5 & 5 & 0.83 & 0.83 & 0.81 & 0.81 \\
\hline 12 & 5 & 5 & 0.83 & 0.83 & 0.81 & 0.81 \\
\hline 13 & 6 & 6 & 1 & 1 & 1 & 1 \\
\hline 14 & 5 & 5 & 0.83 & 0.83 & 0.81 & 0.81 \\
\hline 15 & 5 & 6 & 0.83 & 1 & 0.81 & 1 \\
\hline 16 & 6 & 6 & 1 & 1 & 1 & 1 \\
\hline 17 & 6 & 6 & 1 & 1 & 1 & 1 \\
\hline 18 & 6 & 6 & 1 & 1 & 1 & 1 \\
\hline 19 & 5 & 5 & 0.83 & 0.83 & 0.81 & 0.81 \\
\hline
\end{tabular}

I-CVI Item-level content validity index, $K^{*}$ Modified Kappa index, $R$ removed, $M$ modified

The first important element of PN is responsibility for relationships and decision-making [5, 7]. Experts agreed with the importance of developing direct interpersonal communication with the patient (Item 1; I-CVI =1) and with the caregiver (Item 2; I-CVI $=1$ ). This reflects the actual practice of $\mathrm{PN}$, which incorporates the principles of relationship-based care into daily practice, identifying the primary nurse as responsible for the relationship [7]. In this role, the primary nurse, with the patient and caregivers, identifies the needs of the patients and creates a personalized nursing care plan. Because the PN supports individual care, the experts agreed with the importance of developing a personalized nursing care plan and reported it in clinical documentation (Item 15; I-CVI =1).

Communication among staff members is also an important element of PN. The quality of care depends on the information flow between the patient and all members of the healthcare team. Experts agreed with the necessity to increase communication between the people involved in patient care (Items 9 and 10; I-CVI

Table 4 SCVI/Ave and S-CVI/UA generated from Rounds 1 and 2

\begin{tabular}{lllll}
\hline SCVI/Ave & & & S-CVI/UA & \\
\cline { 1 - 1 } \cline { 5 - 5 } First version & Second version & & First version & Second version \\
\hline 0.83 & 0.93 & 0.47 & 0.58 \\
\hline
\end{tabular}

0.83 ), as well as more accurate information about patients (Item 12; I-CVI $=0.83$ ). PN is about creating healthy partnerships between nurses and other clinicians to best serve patients and their families [7].

Furthermore, managers should support PN organisation. They are committed to creating opportunities for professional growth. They should guarantee that no other nursing care models are performed (Item 8 ; I-CVI = 0.83). They are also committed to the development of clinical staff and the evaluation of nurses' competence to improve quality of care $[5,13]$.

Finally, work allocation and patient assignments are required in $\mathrm{PN}$ care. The nursing care plan must be followed by the other nurses-associate nurses-and the primary nurse can delegate the patient care to the associated care unit in case of absences [7]; the experts agreed with this (Item 4; I-CVI =1). Experts' discussion about "the evidence of primary nurse assignment by nurse coordinator through weekly planning" (first version of Item 7; I-CVI $=0.66$ ) highlights the importance of nurse assignment to patients but not that of frequency of how it is planned. However, they recommended providing the team responsibility assignment with the "evidence of the primary nurse's name in the clinical documentation" (Item 16; I-CVI =1).

This checklist has potential applications in both the research setting and clinical practice. Researchers can 
use this checklist to describe more accurately the PN characteristics and compare results from different research using the same instrument. In clinical practice, the checklist provides a unique instrument to support hospital team members during the PN implementation and evaluation phase. In fact, the discordance and discussions surrounding the manner in which it is implemented [12, 15] suggest the need for a valid guide. Monitoring and evaluating $\mathrm{PN}$ are both strategies that help nurses know when a planned project is not working. An effective PN compliance management system could allow organisations to direct quality improvement actions where the PN is more critical.

This study has some limitations. Although the selection of a panel of experts was carefully made to ensure high-level competency concerning the PN, the preliminary version of the checklist was created by two researchers in nursing science, and they could not identify the entire domain of PN. Moreover, our experts worked in Italian acute hospital settings and specific contexts were not considered. Finally, this checklist should be tested in clinical practice.

\section{Conclusion}

In summary, in this study, we developed a valid checklist for implementing and monitoring $\mathrm{PN}$ compliance in hospital settings. Ongoing monitoring is built into normal, recurring nursing activities for quality improvement. Measuring PN compliance should be applied to provide continuous feedback to nurses. Using this tool could create specific moments of learning and education. Nursing programmes and courses could be considered to maintain adequate nurse competences in PN. Moreover, utilising a valid checklist could permit the comparison of different results by other researchers, which is not currently being done. Future research should be conducted to compare the results from the checklist with nursing outcomes.

\section{Abbreviations}

NCDM: Nursing care delivery models; PN: Primary nursing care model; ICVIs: Content validity index; S-CVI/UA: Scale-level content validity index, universal agreement calculation method; S-CVI/Ave: Scale-level content validity index, averaging calculation method; $P_{C}$ : Probability of a chance occurrence; $\mathrm{K}^{*}$ : Modified Kappa index

\section{Supplementary Information}

The online version contains supplementary material available at https://doi. org/10.1186/s12912-021-00712-1.

Additional file 1.

Additional file 2 .

\section{Acknowledgements}

The authors are grateful to the Center of Excellence for Nursing Scholarship (CECRI) for their support of this collaboration. In addition, we would like to thank Rosa De Angelis Durante, RN, MSN; Miriam De Rinaldis, RN, MSN; and
Lucia Zaino, RN, MSN, Director of the School of Nursing for supporting the organisational development of primary nursing.

\section{Authors' contributions}

$A C$ and $M C$ made substantial contributions to conception and design, acquisition of data, and analysis and interpretation of data. AC, GM, MC, and EC were involved in drafting the manuscript. MZ was involved in revising it critically for important intellectual content and in obtaining final approval of the version to be published. The author(s) read and approved the final manuscript.

\section{Funding}

This study was funded by the Center of Excellence for Nursing Scholarship Rome, Italy (Grant number: 2.20.19). The funding source was not involved in the study design, data collection, analysis, or interpretation. Neither was it involved in writing the manuscript or in the decision to submit the manuscript for publication.

Availability of data and materials

All data generated or analysed during this study are included in the published article.

\section{Declarations}

Ethics approval and consent to participate

Before the study was conducted, approvals were obtained from the Catholic University Ethics Committee (N.0031782/20) where the study was to be conducted. All methods were performed in accordance with regulations of the Institutional Review Board of Catholic University. Written informed consent was sought via a cover letter explaining the purpose of the study and the voluntary nature of participation. Informed consent was obtained from all experts before completing the questionnaire.

Consent for publication

Not applicable.

\section{Competing interests}

All of the authors had no any personal, financial, commercial, or academic conflicts of interest separately.

\section{Author details}

${ }^{1}$ Fondazione Policlinico A. Gemelli IRCCS, 00168 Rome, Italy. ${ }^{2}$ Section of Hygiene, Woman and Child Health and Public health, Università Cattolica del Sacro Cuore, Largo Francesco Vito 1, 00168 Rome, Italy. ${ }^{3}$ European Institute of Oncology, Via Ripamonti, 435 Milan, Italy. ${ }^{4}$ Department of Biomedicine and Prevention, University of Tor Vergata, Via Montpellier 1, 00133 Rome, Italy.

Received: 29 April 2021 Accepted: 23 September 2021

Published online: 04 October 2021

\section{References}

1. Shahzad M, Upshur R, Donnelly P, Bharmal A, Wei X, Feng P, et al. A population-based approach to integrated healthcare delivery: a scoping review of clinical care and public health collaboration. BMC Public Health. 2019;19(1):708

2. Havaei F, MacPhee M, Dahinten VS. The effect of nursing care delivery models on quality and safety outcomes of care: a cross-sectional survey study of medical-surgical nurses. J Adv Nurs. 2019;75(10):2144-55.

3. Tiedeman ME, Lookinland S. Traditional models of care delivery: what have we learned? J Nurs Adm. 2004:34(6):291-7.

4. Parreira P, Santos-Costa P, Neri M, Marques A, Queiros P, Salgueiro-Oliveira A. Work methods for nursing care delivery. Int J Environ Res Public Health. 2021;18(4):2088. https://doi.org/10.3390/ijerph18042088.

5. Moura ECC, Lima MB, Peres AM, Lopez V, Batista MEM, Braga F. Relationship between the implementation of primary nursing model and the reduction of missed nursing care. J Nurs Manag. 2020;28(8):2103-12.

6. Payne R, Steakley B. Establishing a primary nursing model of care. Nurs Manag. 2015;46(12):11-3. 
7. Wessel S, Manthey M. Primary nursing: person-centered care delivery system design: creative health care management. 2015. Available from: https:// books.google.it/books?id=V639sgEACAAJ.

8. Kobayashi K, Ando K, Nakashima H, Machino M, Kanbara S, Ito S, et al. Challenges for joint commission international accreditation: performance of orthopedic surgeons based on international patient safety goals. Nagoya J Med Sci. 2021;83(1):87-92.

9. Ingram TL. Compliance: a concept analysis. Nurs Forum. 2009;44(3):189-94.

10. Murphy N, Canales M. A critical analysis of compliance. Nurs Inq. 2001;8(3): 173-81.

11. Ferrua R, Nelson JW, Gatta C, Croso A, Gilot CB, Dal MA. The impact of the primary nursing model on cultural improvement: a mixed-method study. Creat Nurs. 2016;22(4):259-67.

12. Dal Molin A, Gatta C, Boggio Gilot C, Ferrua R, Cena T, Manthey M, et al. The impact of primary nursing care pattern: results from a before-after study. J Clin Nurs. 2018;27(5-6):1094-102.

13. Naef R, Ernst J, Petry H. Adaption, benefit and quality of care associated with primary nursing in an acute inpatient setting: a cross-sectional descriptive study. J Adv Nurs. 2019;75(10):2133-43.

14. Butler M, Schultz TJ, Halligan P, Sheridan A, Kinsman L, Rotter T, et al. Hospital nurse-staffing models and patient- and staff-related outcomes. Cochrane Database Syst Rev. 2019:4:CD007019. https://doi.org/10.1002/14 651858.CD007019.pub3.

15. Mattila E, Pitkänen A, Alanen S, Leino K, Luojus K, Rantanen A, et al. The effects of the primary nursing care model: a systematic review. J Nurs Care. 2014:3:205. https://doi.org/10.4172/2167-1168.1000205.

16. Glasson J, Chang E, Chenoweth L, Hancock K, Hall T, Hill-Murray F, et al. Evaluation of a model of nursing care for older patients using participatory action research in an acute medical ward. J Clin Nurs. 2006;15(5):588-98.

17. Myers $M$, Parchen $D$, Geraci M, Brenholtz R, Knisely-Carrigan D, Hastings C. Using a shared governance structure to evaluate the implementation of a new model of care: the shared experience of a performance improvement committee. J Nurs Adm. 2013;43(10):509-16.

18. Winslow S, Cook C, Eisner W, Hahn D, Maduro R, Morgan K. Care delivery models: challenge to change. J Nurs Manag. 2019;27(7):1438-44.

19. White MC, Randall K, Capo-Chichi NFE, Sodogas F, Quenum S, Wright K, et al. Implementation and evaluation of nationwide scale-up of the surgical safety checklist. Br J Surg. 2019;106(2):e91-e102.

20. Kramer HS, Drews FA. Checking the lists: a systematic review of electronic checklist use in health care. J Biomed Inform. 2017;71S:S6-S12.

21. Haynes $A B$, Weiser $T G$, Berry WR, Lipsitz SR, Breizat AH, Dellinger EP, et al. A surgical safety checklist to reduce morbidity and mortality in a global population. N Engl J Med. 2009;360(5):491-9.

22. Amaratunge $S$, Harrison M, Clifford R, Seubert L, Page A, Bond C. Developing a checklist for reporting research using simulated patient methodology (CRiSP): a consensus study. Int J Pharm Pract. 2021;29(3): 218-27.

23. Lynn MR. Determination and quantification of content validity. Nurs Res. 1986;35(6):382-5

24. Polit DF, Beck CT. The content validity index: are you sure you know what's being reported? Critique and recommendations. Res Nurs Health. 2006; 29(5):489-97.

25. Polit DF, Beck CT, Owen SV. Is the CVI an acceptable indicator of content validity? Appraisal and recommendations. Res Nurs Health 2007;30(4):459-67.

26. Wynd CA, Schmidt B, Schaefer MA. Two quantitative approaches for estimating content validity. West J Nurs Res. 2003;25(5):508-18.

27. Zamanzadeh V, Ghahramanian A, Rassouli M, Abbaszadeh A, Alavi-Majd H, Nikanfar AR. Design and implementation content validity study: development of an instrument for measuring patient-centered communication. J Caring Sci. 2015:4(2):165-78.

\section{Publisher's Note}

Springer Nature remains neutral with regard to jurisdictional claims in published maps and institutional affiliations.

Ready to submit your research? Choose BMC and benefit from:

- fast, convenient online submission

- thorough peer review by experienced researchers in your field

- rapid publication on acceptance

- support for research data, including large and complex data types

- gold Open Access which fosters wider collaboration and increased citations

- maximum visibility for your research: over $100 \mathrm{M}$ website views per year

At $\mathrm{BMC}$, research is always in progress.

Learn more biomedcentral.com/submissions 